\title{
The Misallocation Problem of Subsidized Housing: A Lesson from Hong Kong
}

\author{
Ka Shing Cheung ${ }^{1}\left(\mathbb{D}\right.$, Siu Kei Wong ${ }^{2, *(\mathbb{C})}$, Kwong Wing Chau $\left.{ }^{2} \mathbb{(}\right)$ and Chung Yim Yiu ${ }^{1}(\mathbb{D}$ \\ 1 Department of Property, The University of Auckland Business School, 1142 Auckland, New Zealand; \\ william.cheung@auckland.ac.nz (K.S.C.); edward.yiu@auckland.ac.nz (C.Y.Y.) \\ 2 Department of Real Estate and Construction, The University of Hong Kong, Hong Kong, China; \\ hrrbckw@hku.hk \\ * Correspondence: skwongb@hku.hk
}

Citation: Cheung, K.S.; Wong, S.K.; Chau, K.W.; Yiu, C.Y. The Misallocation Problem of Subsidized Housing: A Lesson from Hong Kong. Sustainability 2021, 13, 1855. https:// doi.org/10.3390/su13041855

Academic Editors: Jorge Chica-Olmo and Ángeles Sánchez

Received: 31 December 2020

Accepted: 4 February 2021

Published: 8 February 2021

Publisher's Note: MDPI stays neutral with regard to jurisdictional claims in published maps and institutional affiliations.

Copyright: (c) 2021 by the authors. Licensee MDPI, Basel, Switzerland. This article is an open access article distributed under the terms and conditions of the Creative Commons Attribution (CC BY) license (https:/ / creativecommons.org/licenses/by/ $4.0 /)$.

\begin{abstract}
Providing affordable housing has become one of China's key national policy agenda items. The shared-equity model in Hong Kong, implemented since the late 1970s, has assisted many families in owning a home in the public housing market. However, little attention has been paid to their welfare after acquiring their subsidized units. This study aims to examine how shared-equity homeownership distorts residential mobility through in-kind subsidies. Panel data analysis reveals that the more in-kind subsidies owners receive, the longer they would hold on to their units in spite of spatial mismatches. Private owners, on the other hand, would trade their units without such distortion. Conceptually, the lower mobility of assisted owners could be interpreted as a new source of misallocation in Glaeser and Luttmer's welfare analysis. Practically, this throws into question the sustainability of a subsidizing homeownership policy: does the government ultimately want assisted homeowners to move from public housing to private housing in the future (for which high mobility would be intended)? If so, new thinking on how to make in-kind subsidies transferable is needed.
\end{abstract}

Keywords: subsidized homeownership; residential mobility; misallocation; spatial mismatch; panel data estimation

\section{Introduction}

Most welfare analysis of government subsidies follows the standard economic inefficiency argument that when the social surplus falls short of the money used for paying and administering the subsidies, a so-called "deadweight loss" arises—subsidy recipients tend to consume more of a product than they otherwise would. Such analysis typically assumes that the allocative efficiency of subsidies remains the same over time. This is, however, unrealistic when it comes to in-kind subsidies: do recipients who obtained the subsidies a long time ago value the subsidies as much as non-recipients do? If not, such misallocation is another welfare loss that could persist. Subsidized housing is a prime example of in-kind subsidization to promote homeownership. The question is how in-kind housing subsidies lead to misallocation, ignorance of which may result in an over-optimistic view of homeownership policy.

This paper develops a novel empirical strategy, which borrows and extends Glaeser and Luttmer's [1] rent control analysis, to assess the extent of misallocation by comparing the residential mobility (i.e., turnover, or decision to move by selling the unit) of assisted homeowners and private homeowners (In this study, residential mobility and turnover are used interchangeably). Residential mobility can capture not only the inefficiency arising from initial random allocation to eligible recipients [2], but also any spatial mismatches that arise subsequent to initial allocation (e.g., as owners improve their socio-economic status, their existing housing units are no longer good enough) [3]. While both private and assisted owners could suffer from spatial mismatches, only the latter will incur the loss of in-kind subsidies if they move out-an institutional feature that will be explained 
shortly. Private owners, on the other hand, have no institutional barriers to move, so their turnover rates can serve as a 'control' when evaluating how in-kind subsidies distort assisted owners' turnover. One may, however, doubt if private housing is a valid control because its better quality and investability can be attributed to its higher turnover rate. To address this concern, a placebo group called 'privatized housing' is identified-it refers to subsidized housing that has been legally converted into private housing. In other words, privatized housing shares the same quality as subsidized housing but can be sold freely as if the units were private. Comparing the turnover rates of subsidized and privatized housing would provide a strong test of any misallocation due to in-kind subsidies. Table 1 summaries the key differences between the three housing groups.

Table 1. Subsidized, Privatized, and Private Housing.

\begin{tabular}{cccc}
\hline & Subsidized Housing & Privatized Housing & Private Housing \\
\hline Housing Quality & Government standard & Government standard & Market standard \\
Resale Price & Subsidy-dependent & Market-driven & Market-driven \\
\hline
\end{tabular}

The subsidized homeownership model in Hong Kong, known as the Home Ownership Scheme (HOS), is a shared-equity arrangement to help lower-income families own their homes in the public housing market (see Section 3 for more details). The government builds the housing units and subsidizes eligible families to purchase them. The idea behind 'shared equity' is that when assisted homeowners sell their units, they are only allowed to keep the share of selling price proportional to their initial equity contribution, while the rest will go back to the government. However, if they do not sell their units, they can continue to stay without any extra payment to the government. Economically, selling their units is equivalent to forgoing the in-kind subsidies, hence a disincentive to move out until the cost of spatial mismatches (e.g., long commute to work) has reached a level that outweighs the benefit of keeping in-kind subsidies. Our data analysis produces several findings that support the disincentive to move. First, subsidized housing has had a much lower turnover rate than its private counterpart on average, even after accounting for the initial resale restriction period. Second, given the same level of spatial mismatches, owners with more subsidies (in the form of initial purchase discounts) tend to own their units longer. In particular, the panel data estimation suggests that a $1 \%$ increase in the housing subsidy will reduce the transaction turnover by about $2 \%$. Third, when privatized housing is used as a counterfactual test, its turnover rate is no longer jointly determined by spatial mismatches and subsidies as in the case of subsidized housing; rather, it is more correlated with private housing's turnover rate.

\section{Misallocation under Subsidized Homeownership}

Glaeser and Luttmer [1] show that under price control, as price mechanisms can no longer guide the allocation of goods to consumers, the welfare loss due to misallocation could exceed the welfare loss due to undersupply (Figure 1). Section 2 borrows and extends their framework to examine how in-kind housing subsidies, in the form of subsidized homeownership, induce two types of misallocation. Standard welfare analysis demonstrates that imposing a price control (e.g., $\Delta$ below market price) will reduce the quantity relative to the free-market equilibrium, hence undersupply. Such classic deadweight losses are depicted by the area of the triangle $(\mathrm{ABC})$. If price-controlled products are allocated randomly, there will be further welfare losses, captured by the area of the trapezium (AEFG), because the average consumer who is allocated a price-controlled product does not value it as much as those who can freely choose the products they want. This is the misallocation advocated by Glaeser and Luttmer. With randomly (not efficiently) allocated products, the average consumer valuation will be reduced. 


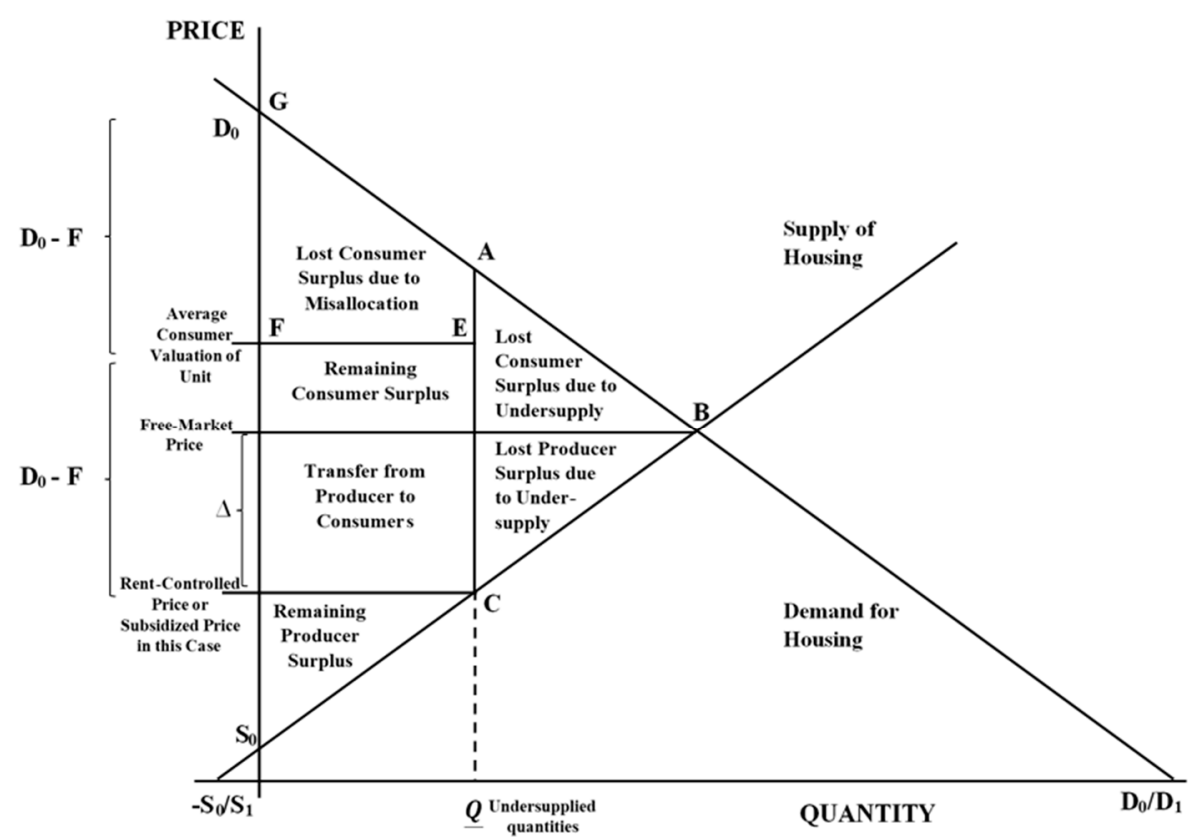

Figure 1. Welfare losses from rent control when apartments are randomly allocated across consumers. Modified by authors based on [1] (p. 1029).

Subsidies are just the flip side of price control. In the case of subsidized homeownership, the trapezium (AEFG) can depict the losses due to initial random assignment (ballot) of housing units to prospective homeowners. For example, the unit most preferred by owner $\mathrm{A}$ is given to $\mathrm{B}$, and the one most preferred by $\mathrm{B}$ is given to $\mathrm{C}$. This, however, is just the initial misallocation. Even if an owner had luckily allocated her most preferred unit, she might subsequently experience spatial mismatches such as changes in work, schooling, family or health status. The current unit is no longer her optimal housing choice, a situation that can be described as ex-post-misallocation. She could, in theory, sell her unit to the highest-valued buyer to eliminate such misallocation. However, the shared equity arrangement will discourage her from doing so because she would then lose the in-kind subsidy. Ex post misallocation would persist—probably also grow over time-such that the "Remaining Consumer Surplus" in Figure 1 would eventually dissipate. This means while it is optimal for individual owners not to move, the market outcome could be sub-optimal as the average consumer valuation for subsidized housing will be further reduced. Empirically, ex post misallocation dictates that assisted owners are unwilling to move unless the cost of spatial mismatches is higher than the benefit of in-kind subsidies, an implication that will be tested in this study.

\section{Background of Subsidized Homeownership in Hong Kong}

While affordable homeownership programs exist in many forms in different countries (e.g. tax-deductible mortgage payments, tenant protection laws, supply-side subsidies for state agencies, and direct grants for housing purchase), the term "shared equity homeownership" has been increasingly used to describe such subsidized homeownership programs according to their nature of finance [4]. Shared equity homeownership means the government offers cash or in-kind housing subsidies to eligible households to buy their properties at a below-market rate. In exchange, the potential capital gain arising from the resale of the unit has to be shared with the government (We used the term subsidized homeownership and shared-equity homeownership interchangeably).

Hong Kong has used the shared equity affordable homeownership policy since the 1970s; it is known as the Home Ownership Scheme (HOS). The HOS program was first launched in 1976 to help low-income people own their homes because Hong Kong's robust and sustained economic growth at the time raised the aspirations of many of its citizens 
for better living conditions, which meant owning, rather than renting, a unit. Since its establishment, the HOS now boasts over 395,000 units, which house about one-third of the owner-occupiers in Hong Kong.

Under the HOS, the government sells newly built units to eligible public housing tenants and low-income residents at discounted prices, usually at 30-50 percent below the market rates for comparable units in the private sector, subject to resale restrictions. After the first three years of ownership, owners can resell their units to public housing tenants. From the sixth year of residence, they can also choose to remove all the resale restrictions and sell their units to any buyers by paying the government a premium proportionate to the original purchase price discount. Those owners who have disposed of their subsidized units will no longer be eligible for any other form of public housing under any circumstance. Therefore, switching between subsidized units is not possible.

To show how the resale of subsidized units works, consider a typical case where the government has sold a unit to an assisted owner at a discounted price equal to $(1-\mathrm{d} \%) \times \mathrm{P} 1$, where $\mathrm{d} \%$ was the discount and P1 was the prevailing market price. The owner is usually not allowed to resell his unit within the first few years of occupancy. Upon the expiration of this restriction period, the owner can resell his subsidized unit, (1) to anybody at a market price (P2) after paying the government a premium equivalent to $\mathrm{d} \%$ of $\mathrm{P} 2$; or (2) to public housing tenants at a negotiated price of about $(1-\mathrm{d} \%) \times \mathrm{P} 2$ (The only difference is that the buyer in the first case will be exempt from having to pay a premium when he resells the unit, whereas the buyer in the second case will still be subject to the premium payment requirement when he resells). Either way, the owner will receive net sale proceeds of approximately $(1-\mathrm{d} \%) \times \mathrm{P} 2$. Assuming no further transaction costs, the owner will make a profit if the housing price has gone up (i.e., P2 > P1) but will incur a loss if the price has gone down (i.e., P2 < P1). This outcome may also be affected by occasional changes made to the discount factor, resale restriction period, etc., as has been evident in the past. In general, given the prolonged upward trend of property prices in Hong Kong, many assisted homeowners should be able to make considerable profits if they resell their units.

Despite this, the data available so far indicate an extremely inactive resale market. Only about $1 \%$ of the total subsidized housing stock is sold to public housing tenants each year, which is far below the $9 \%$ recorded for private housing. Why have so many subsidized units remained "frozen" and unsold to potential buyers? To find out the answers, we consider the initial purchase discount on subsidized units $(\mathrm{d} \%)$ as an in-kind rental subsidy to the owner. We will use panel data analysis to show that the subsidy (initial purchase discount) is the primary factor behind the inverse relationship that exists between housing subsidies and residential mobility.

\section{Research Design}

\subsection{Development of Hypothesis}

The idea behind the misallocation problem of subsidized housing can be better understood using an intuitive case. Suppose a person lives in a subsidized housing far from his workplace. Frustrated by the long commute every day, he considers moving to a more convenient location. If his existing unit were privately owned, he would be better off selling it and buying another one nearby this workplace to save on the commute. However, since he is an assisted homeowner, selling his subsidized unit would de facto give up the in-kind subsidy from the government. As long as the commuting cost does not exceed the in-kind subsidy, he will prefer to stay put and not to move elsewhere. In this sense, if there is a spatial mismatch between where one currently lives and where one prefers to move to, the in-kind subsidy will constitute a disincentive for assisted homeowners to relocate. Such a mismatch could arise from a commute being too long, a unit being too small, or a district not having famous schools, etc.

This illustration can be economically modeled as a residential location choice, where a household's decision to relocate hinges on the discounted net return from relocation at a particular time. Psychological or sentimental factors are assumed to be idiosyncratic. If the 
net return is positive, the household will tend to move, and vice versa [5]. Consider first the case without government subsidies. The relocation decision involves comparing the imputed rental costs involved in the existing residence $\left(R_{u}\right)$ and an alternative location $\left(R_{m}\right)$. The costs are 'imputed' because the household is assumed to be an owner-occupier who leases back his premises (since HOS owners are allowed to rent out their subsidized units only after payment of a land premium to the government, it is reasonable to assume that they are owner-occupants). If $R_{u} \geq R_{m}$, a mismatch arises, and the household will move to eradicate the mismatch; otherwise, the household will stay. Even if there is no mismatch at the beginning, as time goes by, a mismatch is likely to arise and become more apparent due to changes in personal circumstances (e.g., a bigger unit is needed after marriage) or in the neighborhood (e.g., a waste disposal facility is built nearby). All these changes will induce a more significant mismatch, thereby giving the household more incentive to move.

Next, consider the case with government subsidies. Suppose the government offers a rental subsidy, $S$. Whether or not the household will move is dependent on the relative size of $R_{u}+S$ and $R_{m}$. It is only when the rental cost of staying in the existing place becomes too high (i.e., $R_{u}+S \geq R_{m}$ ) that the household will decide to move. In other words, when a mismatch occurs, a larger subsidy provides a disincentive for a household to move, as if he were "compensated" to tolerate the mismatch. In the shared equity model, the stream of rental subsidies can be thought of as the percentage discount to the price of a subsidized unit $(d \%)$ offered by the government at the time of purchase. This can be translated into a key testable hypothesis of this study:

In-kind Subsidy Hypothesis. Ceteris paribus, the larger the in-kind subsidy (price discount) offered by the government, the less likely the homeowner will move; thus, a lower residential mobility will result even with spatial mismatches.

More specifically, households facing a spatial mismatch are 'trapped' in their existing units, giving rise to a subsidized housing market with low turnover. It does not only increase the commuting cost of assisted owners but also prevents the subsidized units from being reallocated to others in need. Although the urban economics literature contains many residential mobility studies, little attention has been paid specifically to institutional factors, notably the distorted incentives caused by housing subsidy programs. In the ensuing subsection, the panel data estimation strategy will be presented, with an aim to mitigate any unobservable bias and control for any confounding factors affecting households' relocation decisions [6-9].

\subsection{Empirical Model Setup}

To begin with, it is essential to decide how to measure and compare residential mobility in the resale market for subsidized housing. Several measures have often been proposed to infer the degree of residential mobility: these include the length of residence, the likelihood of a household moving, the sellers' and buyers' time-on-market, and the turnover of housing/dwellings [10-13]. For this study, the turnover of housing units is used. Since longitudinal data on household relocation is not available, it is impossible to identify which assisted owners have sold their units and made their way into the private market. As the second-best solution, the turnover rate of subsidized units at the 'building block' level is used to measure residential mobility. The turnover rate $\left(T_{i t}\right)$ is defined as the proportion of units traded out of total housing stock in the building block $i$ at time $t$ :

$$
T_{i t}=\frac{V O L_{i t}}{\text { STOCK }_{i t}} \times 100 \%
$$

where $V O L_{i t}$ is the number of subsidized units traded and $S T O C K_{i t}$ is the number of subsidized units (stock) available. The subsidized housing stock could change over time for two reasons. First, units subject to the initial resale restriction period should not be counted; their turnover is by definition zero as resale is not allowed. Second, as time goes by, some subsidized units would leave the shared equity model and can be traded as if they 
were private (which we called 'privatized housing'). It is, therefore, necessary to ensure that the denominator is accurate when measuring the turnover rate.

To consider the effects of spatial mismatches and in-kind subsidies (percentage price discounts) on turnover, the following regression model is specified:

$$
T_{i t}=b_{0}+b_{1} M_{I} S_{i t}+b_{2} \text { MIS }_{i t} \times d \%_{i}+Z_{i t}+\varepsilon_{i t}
$$

where $M I S_{i t}$ is a vector of mismatch measures; $d \%_{i}$ is the in-kind subsidies (percentage price discounts); $Z_{i t}$ is other spatial-temporal factors that could affect turnover rate; $\varepsilon_{i t}$ is a random error; and $b_{0}, b_{1}$, and $b_{2}$ are the coefficients to be estimated. It should be noted that the variable $d \%$ does not enter into Equation (2) on its own because it is not time-varying and will become part of the fixed effect as we will see in Equation (5).

Regarding the mismatch variable $\left(M I S_{i t}\right)$, since direct observation is not possible, three different measures are used as a proxy-based on the spatial mismatch literature [14], as specified in Equation (3). The first measure is related to work-induced mismatches. As discussed in our motivating example, mismatches may arise from a long commute to work. Households working across districts usually incur higher transportation and time costs. To capture such a work-induced mismatch, the proportion of working households who have to commute to another district for work (i.e., WORKD) is used (later on, we will have another measure, ACCESS, which captures the actual travel time between districts as a further test). Higher WORKD indicates a higher chance of work-related mismatches. The second measure is related to income-induced mismatches. As the income of households increases, they may want to upgrade from subsidized housing to the better-quality private housing and enjoy a higher standard of living. Per capita income of households living in subsidized housing $\left(I N C_{i t}\right)$ is used as a proxy. Higher $I N C$ indicates a higher chance of income-related mismatches. The third measure is related to amenity-induced mismatches. Assisted owners may want to move to another neigborhood with better amenities, e.g., a better school or transportation network. The hedonic literature establishes that housing prices are capable of capitalizing such amenities [15-18] or externalities [19]. Relative housing prices between neighborhoods can therefore provide a ranking of the overall amenity level—a lower-price neighborhood has a lower amenity level and potentially suffers more from amenity-induced mismatches than a higher-price neighborhood. The proxy here is 'house price relative' $\left(H P R_{i t}\right)$, which is defined as the ratio of the average price of all private housing in Hong Kong at time $t$ to the average private housing price of a particular neighborhood at the same time. HPR $<1$ means that the neighborhood has a better amenity level than the Hong Kong average (which induces people to stay), while HPR > 1 refers to an amenity level lower than average (which triggers people to leave).

Apart from the three proxies above, the length of time over which a household has lived in subsidized housing could also matter. In general, the longer the time, the more likely a mismatch arises due to changes in individual circumstances. For subsidized homeownership, since a household's decision to move is the same as its decision to sell, we can, in principle, include an additional mismatch variable to measure the holding period of subsidized units $\left(L E N_{i t}\right)$. However, as we will show later, such a length-of-time mismatch will be eliminated when it comes to the first-differenced panel estimation. Nevertheless, for completeness, the full vector of mismatch measures is specified:

$$
M I S_{i t}=c_{1} W_{\text {WRKD }}+c_{2} I N C_{i t}+c_{3} H P R_{i t}+c_{4} L E N_{i t}
$$

where $c_{1}, c_{2}, c_{3}$, and $c_{4}$ are estimated coefficients. According to our In-kind subsidy Hypothesis, a larger discount should reduce the mismatch effects or make households more tolerant of the mismatches. As a result, $b_{2} \cdot c_{1}, b_{2} \cdot c_{2}, b_{2} \cdot c_{3}$, and $b_{2} \cdot c_{4}$ are expected to be negative.

Another challenging task is to control for other unobservable determinants of turnover rates (e.g., financial consideration). From the literature, the turnover rate is known to vary with property price levels [20] and property quality [21]. This means $Z_{i t}$ can be broken down 
into a temporal effect $\left(Z_{t}\right)$ and a cross-sectional effect $\left(Z_{i}\right)$, assuming that the covariance of both variables is independently and identically distributed:

$$
Z_{i t}=Z_{t}+Z_{i}
$$

$Z_{t}$ can be approximated by the turnover rate of the private housing market at time $t$ in a 'hot' market, more people want to buy and sell. Finding a good measure for $Z_{i}$ is not straightforward. Some subsidized housing estates could have higher turnover than others due to quality differences such as building age and location. It is difficult, however, to fully identify such quality attributes. An alternative solution, as this study proposes, is to use a first-differenced panel data approach to eliminate any cross-sectional variation in quality over time:

$$
\Delta T_{i t}=a+b_{1} \Delta M I S_{i t}+b_{2} \Delta M I S_{i t} \times d \%_{i}+b_{3} \Delta Z_{i t}+\Delta \varepsilon_{i t}
$$

Equation (5) is the first-difference of Equation (2), so all the time-dependent variables are prefixed by a time change operator $\Delta Z_{i}$, including unobserved quality, are eliminated in the differencing process, except for building age, which increases with a constant unit of time. As a difference of two consecutive periods is always equal to one, the constant term will capture this building age effect. The coefficients in Equation (5) are expected to have the same sign as those of Equation (2). $\Delta Z_{i t}$ is the change in the turnover rate of private housing within the immediate $400-\mathrm{m}$ radius circle of a subsidized housing estate at the same period $t$. This should help control for most, if not all, unobservable factors that could potentially affect turnover.

\subsection{The Panel Data}

Measuring residential mobility by the turnover of subsidized units is intuitive. This measure provides us with bottom-up information on household movements (Previous studies used a small (5\%) sample of census data to model whether a household has changed homes in the past five years [22-24], but their data did not contain subsidy levels and distinguish between subsidized and privatized units). The dataset used in this study comes primarily from the Economic Property Research Centre (EPRC) and the Population Census by the Hong Kong Census and Statistics Department. The data covers all property transactions filed by the Land Registry (the official property title registration system) in Hong Kong, including those for subsidized units that have been "privatized" and resold in the open market. The data from the Hong Kong Population Census are available in several different formats. For this study, the data used are based on the building block levels of subsidized housing estates. It is worth noting that the household samples of the Census are surveyed from the same building block. Although it represents panel data at the building level, it does not necessarily involve the same set of households for each Census. Such data refer to an average measurement. Nevertheless, suffice to say that the Census contains all the essential data on household characteristics, including income and demographic attributes at the building block level.

The background of the Hong Kong subsidized sales housing market can be observed from the summary statistics of the variables in Panels (A) and (B) of Table 2. First, as Panel (A) shows, the trading volume (VOL) of subsidized housing averaged 3.49 transactions per building block per year, with a turnover $(T \%)$ of $1.09 \%$. This is considerably smaller than the $4.53 \%$ turnover rate recorded for privatized housing, even though quality is the same. Welch t-test result in the last column of Panel (A) confirms that the difference is statistically significant, providing preliminary evidence that the residential mobility of subsidized housing is lower. 
Table 2. Definition of Variables and Their Descriptive Statistics.

\begin{tabular}{|c|c|c|c|c|c|c|}
\hline \multicolumn{7}{|c|}{ Panel (A)-Measure of Residential Mobility } \\
\hline \multirow[b]{2}{*}{ Variable } & \multirow[b]{2}{*}{ Description } & \multicolumn{2}{|c|}{ Subsidized (1) } & \multicolumn{2}{|c|}{ Privatized (2) } & \multirow{2}{*}{$\begin{array}{c}\begin{array}{c}\text { Diff. } \\
(2)-(1)\end{array} \\
t \text {-test }\end{array}$} \\
\hline & & Mean & S.D. & Mean & S.D. & \\
\hline$T \%$ & Turnover rates (transactions per annum as \% of housing stock) & 1.09 & 1.12 & 4.53 & 5.57 & $73.2 * *$ \\
\hline$V O L$ & No. of transactions per annum & 3.49 & 3.90 & 1.06 & 2.25 & $-66.3 * *$ \\
\hline STOCK & No. of units in a building block & 306 & 156 & 22 & 37 & $-218.7^{* *}$ \\
\hline \multicolumn{7}{|c|}{ Panel (B)—Measures of In-kind Subsidies, Mismatches, and Controls } \\
\hline & & \multicolumn{4}{|c|}{ Subsidized and Privatized } & Private \\
\hline Variable & Description & Mean & S.D. & Min. & Max. & Mean \\
\hline$d \%$ & Percentage price discount as a proxy of in-kind subsidies & 36.19 & 9.94 & 13.25 & 50.00 & - \\
\hline WORKD & Proportion of workers who commute to another district for work (\%) & 77.7 & 10.3 & 33.2 & 99.3 & 70.4 \\
\hline ACCESS & $\begin{array}{l}\text { District-level accessibility index that measures the average travel time to other } \\
\text { districts weighted by working population (Furtherest North District }=100 \text { ) }\end{array}$ & 69.5 & 12.8 & 48.6 & 100 & - \\
\hline INC & Median monthly household income (HK\$) & 23,865 & 9081 & 5758 & 211,954 & 27,090 \\
\hline$H P R$ & $\begin{array}{l}\text { Housing price relative (i.e., private housing price in Hong Kong relative to } \\
\text { private housing price of a neighborhood) }\end{array}$ & 1.11 & 0.37 & 0.26 & 2.56 & 1.00 \\
\hline \multirow[t]{2}{*}{ PRIVATRADE } & $\begin{array}{c}\text { Turnover rate }(\%) \text { of comparable private housing }(<\mathrm{HK} \$ 8 \mathrm{M} ;<400 \mathrm{~m} \text { radius of } \\
\text { subsidized housing units) }\end{array}$ & - & - & - & - & 5.46 \\
\hline & No. of Observations & 15,156 & 15,156 & 15,156 & 15,156 & - \\
\hline
\end{tabular}

Notes: The sample period is from 1997 to 2014; 842 building blocks of subsidized housing are covered in the sample. Hence, the sample includes 15,156 observations (i.e., $842 \times 18$ ). The residential mobility measure in Panel (A) is calculated according to the data from the Land Registry and Economic Property Research Center (EPRC), while the mismatch measures in Panel (B) are based on 2001, 2006, and 2011 Census. The data for years in between are obtained by linear extrapolation. All variables indicate the average of building block $i$ for each year. "**" means the coefficient is significant at the $1 \%$ level.

As for Panel (B) of Table 2, the percentage price discount ( $(\%$, i.e., the housing subsidy) of subsidized housing amounts to $36 \%$ on average, with some cases reaching a maximum of $50 \%$. Generally speaking, the average household size of subsidized housing is larger than that of their private counterparts, probably revealing a denser living condition. Regarding the extent of mismatches among assisted owners, WORKD indicates that around $78 \%$ of assisted owners worked outside their home districts, exceeding $70 \%$ for private owners. Figure 2 graphically illustrates such a spatial mismatch. The dots represent the locations of subsidized housing. Those in red indicate that almost $80 \%$ of residents need to travel across districts for work. To a certain extent, the figures reveal that HOS households' transportation costs (around 6-8\% of total household expenditure) are higher than those of their private housing counterparts.

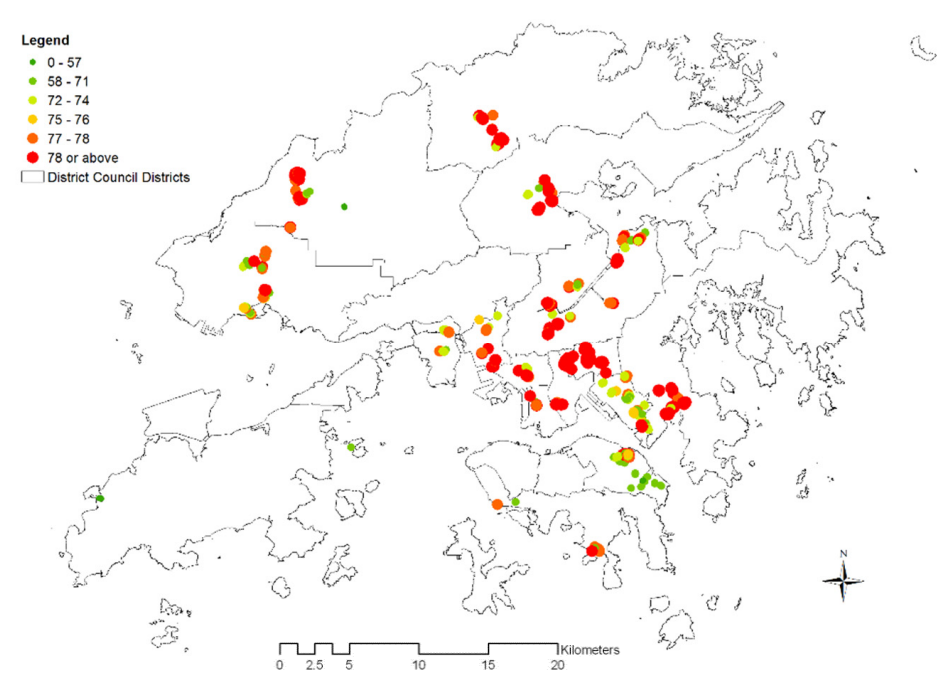

Figure 2. Spatial distribution of subsidized housing and \% of residents working in other districts (WORKD). Authors' compilation based on 2001, 2006, and 2011 Hong Kong Population Census. 
The income of households (INC) captures income-induced mismatches. When household income increases, there is a greater incentive for a household to trade up and move to better quality private housing. The data indicate a median monthly household income (INC) for subsidized housing at around HK\$23,900, which is lower-only by about $10 \%$ than those living in private housing. Some of these assisted owners can well upgrade to private housing, but somehow, they did not do so. The housing price relative (HPR) captures amenity-induced mismatches. The average value of 1.11 suggests that subsidized housing is generally located in neighbourhoods with a lower-than-average amenity level.

Finally, the turnover rate of the comparable private housing (PRIVATRADE) is added to the estimation as another control. This variable PRIVATRADE is defined as the turnover rate $(T \%)$ of private housing for which the consideration is less than $\mathrm{HK} \$ 8$ million and within the immediate 400-m radius circle (5-min walk) of subsidized housing (Further studies on the circle size could be done [19]). These selection criteria ensure that the control (private housing) is comparable to subsidized housing in terms of location and prices (the most expensive subsidized unit was sold for around HK\$8 million). As expected, even with similar location and prices, the average turnover rate of private housing (5.5\%) is much higher than subsidized housing (1.1\%) but is closer to privatized housing ( $4.5 \%)$.

\section{Empirical Results}

\subsection{Baseline Results}

Table 3 present the panel estimation results. Hausman tests generally prefer fixed effects to random effects. For models (4) and (8), although the chi-square statistics are marginally significant at $10 \%\left(\chi^{2}=5665 ; \chi^{2}=9502\right)$, we decided to use the fixed-effect estimators because 1) the efficiency gain in random-effect estimators is likely to be modest while their finite sample properties could be worse [25], and 2) if the variable of interest is not orthogonal to the error term, random-effect estimation would be inappropriate (Breusch-Pagan LM test and Pesaran scaled LM test both suggest that time-invariant unobservables are related to our regressors). Columns (1) to (4) use the change of the turnover rate of subsidized units as the dependent variable. Different mismatch proxies, namely $\triangle W O R K D, \triangle I N C$, and $\triangle H P R$, are separately tried in Columns (1) to (3), while all of them are used in Column (4). It is worth noting that the first-differenced panel eliminates the variable $L E N$. To rule out any endogeneity concerns, all mismatch proxies are lagged by one period. Regardless of the model specification, all estimated coefficients for the lagged mismatch measures, i.e., $\triangle W O R K D, \triangle I N C$, and $\triangle H P R$, are statistically significant with positive signs, indicating that assisted owners do in fact respond to our mismatch proxies, though only up to a certain extent.

In developing our In-kind subsidy Hypothesis, it was pointed out that while mismatches should lead to higher turnover rates, the in-kind housing subsidy, as manifested by the percentage price discount $(d \%)$, acts as an opposing force to offset the mismatch effects and hence reduces the turnover. The interaction terms between the initial purchase discounts and mismatch variable measures $(d \% \times \Delta M I S)$ in Columns (1) to (4) demonstrate an expected significantly negative result which points to such offsetting effects in our sample. Moreover, it is worth noting that the first-differenced panel has also eliminated the variable $d \%$ as the percentage price discount does not change over time. Indeed, the cross-sectional fixed effect is also added to the models as a control.

From the panel data results, it is observed that the marginal effect of the housing subsidy (percentage price discount) on turnover is about -0.07 (i.e., the sum of coefficients for the interaction terms with $d \%$ ). The estimation results can be interpreted as elasticities, i.e., the responsiveness of the change in turnover to the change of the housing subsidy. Based on the average turnover rate (i.e., 1.09\%) and percentage price discount (i.e., 36\%), the arc elasticity of the transaction turnover with respect to the housing subsidy is estimated at around 2.4\% (Based on the panel data estimates, the arc elasticities of turnovers with respect to subsidies are estimated as follows: $\left.\bar{\epsilon}=\frac{0.36+(0.36+0.01)}{1.09+(1.09-0.07)} \times \frac{0.07}{0.01}=2.4\right)$. This implies that a $1 \%$ increase in the housing subsidy will reduce turnover by about $2 \%$. 
Table 3. Results of the panel data estimations.

\begin{tabular}{|c|c|c|c|c|c|c|c|c|}
\hline \multirow[b]{2}{*}{$\Delta$ Panel Eq. Variable } & \multicolumn{4}{|c|}{$\Delta$ (Subsidized Housing Turnover in $\%$ ) } & \multicolumn{4}{|c|}{$\Delta$ (Privatized Housing Turnover in \%) } \\
\hline & (1) & (2) & (3) & (4) & (5) & (6) & (7) & (8) \\
\hline \multicolumn{9}{|c|}{ Mismatch Effect } \\
\hline \multirow[t]{2}{*}{$\triangle W O R K D(-1)$} & $0.037 * *$ & - & - & $0.047^{* *}$ & -0.077 & - & - & -0.095 \\
\hline & $(0.007)$ & - & - & $(0.007)$ & $(0.047)$ & - & - & $(0.048)$ \\
\hline \multirow[t]{2}{*}{$\Delta \ln (\operatorname{INC}(-1))$} & - & $0.995^{* *}$ & - & $1.519 * *$ & - & 0.258 & - & -2.971 \\
\hline & - & $(0.214)$ & - & $(0.244)$ & - & $(2.007)$ & - & $(2.216)$ \\
\hline \multirow[t]{2}{*}{$\triangle H P R(-1)$} & - & - & $0.544^{* *}$ & $0.607 * *$ & - & - & -2.377 & -1.865 \\
\hline & - & - & $(0.138)$ & $(0.153)$ & - & - & $(2.097)$ & $(2.060)$ \\
\hline \multicolumn{9}{|c|}{ Subsidy Effect } \\
\hline \multirow[t]{2}{*}{$d \% \times \triangle W O R K D(-1)$} & $-0.001 * *$ & - & - & $-0.002^{* *}$ & $0.003^{* *}$ & - & - & $0.003^{* *}$ \\
\hline & $(0.000)$ & - & - & $(0.000)$ & $(0.001)$ & - & - & $(0.001)$ \\
\hline \multirow[t]{2}{*}{$d \% \times \Delta \ln (\operatorname{INC}(-1))$} & - & $-0.036^{* *}$ & - & $-0.053^{* *}$ & - & $-0.223 * *$ & - & -0.097 \\
\hline & - & $(0.007)$ & - & $(0.008)$ & - & $(0.068)$ & - & $(0.080)$ \\
\hline \multirow[t]{2}{*}{$d \% \times \triangle H P R(-1)$} & - & - & $-0.016^{* *}$ & $-0.018^{* *}$ & - & - & 0.103 & 0.078 \\
\hline & - & - & $(0.005)$ & $(0.005)$ & - & - & $(0.057)$ & $(0.054)$ \\
\hline \multirow[t]{2}{*}{$\triangle P R I V A T R A D E$} & $0.018 * *$ & $0.018^{* *}$ & $0.019 * *$ & $0.019 * *$ & $0.521^{* *}$ & $0.514 * *$ & $0.433^{* *}$ & $0.531 * *$ \\
\hline & $(0.002)$ & $(0.002)$ & $(0.001)$ & $(0.002)$ & $(0.032)$ & $(0.031)$ & $(0.030)$ & $(0.032)$ \\
\hline \multirow[t]{2}{*}{ Constant } & $-0.047^{* *}$ & $-0.074^{* *}$ & $-0.072 * *$ & $-0.069 * *$ & -0.020 & 0.007 & $0.387^{* *}$ & 0.119 \\
\hline & $(0.009)$ & $(0.009)$ & $(0.009)$ & $(0.010)$ & $(0.067)$ & $(0.070)$ & $(0.061)$ & $(0.081)$ \\
\hline Fixed effects? & Yes & Yes & Yes & Yes & Yes & Yes & Yes & Yes \\
\hline Observations: & 13360 & 13360 & 13360 & 13360 & 7133 & 7133 & 7133 & 7133 \\
\hline Adjusted $\mathrm{R}^{2}$ & 0.011 & 0.009 & 0.009 & 0.014 & 0.054 & 0.054 & 0.056 & 0.058 \\
\hline
\end{tabular}

Notes: The dependent variable is the change in turnover rates of subsidized and privatized owners, respectively. "*** means the coefficients are at the $1 \%$ significance level. Standard errors are presented in the parentheses. $\Delta$ (variable $(-1)$ ) represents the difference-lag operator, such as $\Delta \mathrm{X}(-1)=\mathrm{Xt}-1-\mathrm{Xt}-2$. The variable $\mathrm{d} \%$ refers to the percentage price discount (i.e., the in-kind subsidy). WORKD is the proportion of workers who commute to another district for work (\%). It measures the work-induced mismatch. INC represents the per capita monthly household income, which captures the income-induced mismatch. HPR is the housing price relative that proxies the amenity-induced mismatch. HPR $<1$ means that the district is of better quality than the Hong Kong average, while HPR $>1$ refers to the opposite. The variable $\triangle$ PRIVATRADE in \% represents a change of the private housing turnover rate that has a value of less than HK\$8 million and is within the immediate 400-m radius of subsidized housing. The observations are fewer than those in Table 2 due to the use of time differencing and time lags.

Meanwhile, the variable $\triangle P R I V A T R A D E$, which is used to control another unobservable effect (e.g., financial considerations) on the turnover rate $\left(\Delta Z_{i t}\right)$ in Equation (5), is positively significant for both subsidized and privatized HOS markets. The significant coefficients of $\triangle P R I V A T R A D E$ also indicate that the variable effectively captures the spatialtemporal effect $\left(Z_{i t}\right)$, in particular the potential supply and market trends at the district and in the period, because the private housing units are indeed potential competitors in the housing supply.

\subsection{Robustness Tests}

\subsubsection{Privatized Housing as a Counterfactual Test}

As a counterfactual test, we have repeated the panel estimations with privatized housing, which has the same quality as subsidized housing but is not subject to the shared-equity arrangement. Owners of privatized housing are no longer subsidized and should not be concerned about, or be less sensitive to, the percentage price discount ( $\mathrm{d} \%)$. In this connection, a set of affirmative results is found in Columns (5) to (8) of Table 3. The interaction terms between percentage price discounts and the mismatch variables $(\mathrm{d} \% \times \Delta \mathrm{MIS})$ are either insignificant or have the wrong sign. Also, these privatized owners seem unresponsive to spatial mismatches, as the mismatch effects are insignificant. Rather, the much larger coefficient of $\triangle$ PRIVATRADE in Columns (5)-(8) than (1)-(4) suggests that privatized housing behaves more like private housing than subsidized housing does. A plausible explanation is that the turnover decisions of both privatized and private owners are driven more by financial considerations than by spatial mismatches. 


\subsubsection{Alternative Measure of Spatial Mismatches}

To measure the spatial mismatch, our use of the proportion of people working across districts (WORKD) may cause concern that the variable may consider a particular dimension of spatial mismatch, e.g., commute frequency across districts, while overlooking the time cost to commute. Nevertheless, since Hong Kong census data do not provide information on residents' place of work, a direct measure of time cost is impossible. Instead, a district-level "accessibility index" is constructed using the average travel time to other districts weighted by the working population (see Appendix A for how such an index is formulated). After the accessibility indices for 18 council districts are compiled, the index values are then weighted by the working population of the district to replenish the deficiency of relying merely on the single variable WORKD to proxy the commuting mismatch. Table 4 shows that the estimation results remain intact after replacing WORKD with ACCESS. The crosscheck provides further support to our hypothesis-the coefficient of the interaction term $d \% \times \triangle A C C E S S(-1)$ is negative and significant for subsidized housing, but positive and significant for privatized housing.

Table 4. Results of the panel data estimations by replacing WORKD with ACCESS.

\begin{tabular}{|c|c|c|c|c|}
\hline \multirow[b]{2}{*}{$\Delta$ panel eq. variable: } & \multicolumn{2}{|c|}{$\begin{array}{c}\Delta \text { (Subsidized Housing } \\
\text { Turnover in \%) }\end{array}$} & \multicolumn{2}{|c|}{$\begin{array}{c}\Delta \text { (Privatized Housing } \\
\text { Turnover in \%) }\end{array}$} \\
\hline & $\left(1^{\prime \prime}\right)$ & $\left(4^{\prime \prime}\right)$ & $\left(5^{\prime \prime}\right)$ & $\left(8^{\prime \prime}\right)$ \\
\hline \multicolumn{5}{|c|}{ Mismatch Effect } \\
\hline \multirow[t]{2}{*}{$\triangle A C C E S S(-1)$} & $0.049^{* *}$ & $0.063^{* *}$ & -0.034 & -0.080 \\
\hline & -0.009 & -0.009 & -0.066 & -0.0672 \\
\hline \multirow[t]{2}{*}{$\Delta \ln (\operatorname{INC}(-1))$} & - & $1.518^{* *}$ & - & -2.419 \\
\hline & - & -0.239 & - & -2.135 \\
\hline \multirow[t]{2}{*}{$\triangle H P R(-1)$} & - & $0.604^{* *}$ & - & -1.784 \\
\hline & - & -0.152 & - & -2.06 \\
\hline \multicolumn{5}{|c|}{ Subsidy Effect } \\
\hline \multirow[t]{2}{*}{$d \% \times \triangle A C C E S S(-1)$} & $-0.001^{* *}$ & $-0.002^{* *}$ & $0.003 * *$ & $0.003 * *$ \\
\hline & 0 & 0 & -0.001 & -0.001 \\
\hline \multirow[t]{2}{*}{$d \% \times \Delta \ln (\operatorname{INC}(-1))$} & - & $-0.053^{* *}$ & - & -0.097 \\
\hline & - & -0.008 & - & -0.08 \\
\hline \multirow[t]{2}{*}{$d \% \times \triangle H P R(-1)$} & - & $-0.018^{* *}$ & - & 0.078 \\
\hline & - & -0.005 & - & -0.054 \\
\hline \multirow[t]{2}{*}{$\triangle P R I V A T R A D E$} & $0.018^{* *}$ & $0.019^{* *}$ & $0.521 * *$ & 0.531 ** \\
\hline & -0.002 & -0.002 & -0.032 & -0.032 \\
\hline \multirow[t]{2}{*}{ Constant } & $-0.047^{* *}$ & $-0.069^{* *}$ & -0.020 & 0.119 \\
\hline & -0.009 & -0.01 & -0.067 & -0.081 \\
\hline Fixed effects? & Yes & Yes & Yes & Yes \\
\hline Observations: & 13360 & 13360 & 7133 & 7133 \\
\hline Adjusted $\mathrm{R}^{2}$ & 0.011 & 0.014 & 0.054 & 0.058 \\
\hline
\end{tabular}

Notes: This table extends the results of Table 3 by replacing WORKD with ACCESS. Only the relevant columns, namely (1), (4), (5), and (8), are reported. The observations are fewer than that in Table 2 due to time differencing and time lags. "**" means the coefficients are at the $1 \%$ significance level.

\section{Conclusion and Policy Discussion}

The housing market reform in China over the past four decades has significantly improved the overall living conditions of urban households. Now, China is at a critical phase of further developing its housing market to address the growing problem of housing unaffordability and inequality, especially in major cities. Providing affordable housing has, therefore, become one of the most salient items in the national policy agenda. A growing literature has sought to understand the dynamics and consequences of the recent shift in housing policy. Yet, many fundamental questions remain. For instance, should homeownership be subsidized by the government? After assisting households in acquiring affordable housing ownership, does the government want them to move on to private 
housing once their socio-economic status has improved (for which high residential mobility is intended)? If not, does the government have a sustainable source of income and land to build more affordable housing to satisfy new demand?

The subsidized homeownership experience from Hong Kong can shed light on these questions. This study analytically illustrated that the shared equity model could generate welfare losses through ex post misallocation-in-kind subsidies increase assisted owners' opportunity cost of moving. Our key finding confirms that the more in-kind subsidies owners receive, the longer they would hold on to their units in spite of spatial mismatches. The lack of residential mobility has become a significant source of inefficiency and inequity in the public housing market. Ignoring such a consequence may result in an over-optimistic view of subsidized homeownership and an unsustainable housing policy.

In the shared equity model, a critical factor that affects owners' moving decision is the requirement to repay a share of the property price to the government upon resale of the subsidized unit. The share is proportional to the initial subsidy provided by the government. The bigger the initial purchase discount was, the bigger the repayment to the government would be. Different interesting ideas have been proposed.

One is to ask the government to waive the repayment requirement [26]. This would be a windfall to existing assisted owners and provide them with a strong incentive to take profits by moving out - a smart and straightforward solution to residential immobility. The drawbacks of this solution are (1) the loss of government income, which could in principle be used to fund new affordable housing and (2) a negative impression that assisted owners, who are already better off than renters, are benefited twice: first when they bought the subsidized unit and second when they sold it.

Another idea is to impose a time limit on subsidized homeownership [27]. Instead of perpetual ownership, assisted owners only own the subsidized units for a specified period of time, after which the units have to be returned to the government. As the price of subsidized units declines over time, the in-kind subsidies will also get smaller, thereby weakening the disincentive to move. The government will not suffer a loss as she will get back the units (and land) at the end. However, assisted owners would be worse off because they may not be able to afford private housing after selling their subsidized units at declining prices or upon expiry of the subsidized homeownership period.

There is a third idea developed in this study. Under the shared equity model, a moving-out decision is a joint decision to give up (1) the subsidized unit and (2) the ongoing housing subsidy. If the two can be unbundled, then the latter would no longer be a disincentive to move [28]. For example, when assisted owners sell their subsidized units, let them keep the subsidies to purchase another unit in the private market. They only have to repay the subsidies to the government when they resell their private units (This third idea is a modified solution [29]). This arrangement to increase the flexibility of in-kind subsidies resembles the idea of housing vouchers, which give recipients a wider choice of housing units and hence a substantial improvement in their well-being [30]. In any case, while our economic analysis has highlighted in-kind subsides as an obstacle to residential mobility, the moving decision of individual households is also shaped by a complex set of psychological and social factors not observed in this study. Further research is needed to look into these factors in relation to other root problems such as housing inequality and social exclusion [31].

Author Contributions: Conceptualization, K.S.C. and S.K.W.; methodology, K.S.C. and S.K.W.; software, K.S.C; formal analysis, K.S.C. and S.K.W.; data curation, K.S.C.; writing-original draft preparation, K.S.C.; writing - review and editing, S.K.W., K.W.C. and C.Y.Y.; visualization, K.S.C.; supervision, S.K.W. and K.W.C.; project administration, S.K.W. and K.W.C.; funding acquisition, S.K.W. and K.W.C. All authors have read and agreed to the published version of the manuscript.

Funding: This research was funded by the Research Grant Council of Hong Kong, General Research Fund with grant number 17612017.

Institutional Review Board Statement: Not applicable. 
Informed Consent Statement: Not applicable.

Data Availability Statement: Publicly available datasets were analyzed in this study. This data can be found here: https:/ / www.housingauthority.gov.hk/en/home-ownership/hos-secondarymarket/transaction-records/index.html.

Acknowledgments: A research visit was supported by the U.S. Government's Fulbright Program (IIE Grant no: PS00213217).

Conflicts of Interest: The authors declare no conflict of interest. The funders had no role in the design of the study; in the collection, analyses, or interpretation of data; in the writing of the manuscript, or in the decision to publish the results.

\section{Appendix A.}

\section{Appendix A.1. Accessibility Index of 18 District Council Districts in Hong Kong}

When tenure choices are considered, locational accessibility is an important aspect. This is particularly so in Hong Kong, where significant housing price differentials are observed just a mile away from the Mass Railway Transit. In order to measure the influence of time cost for proxying the spatial mismatch, an accessibility index for 18 District Council Districts in Hong Kong is constructed. Specifically, this accessibility index is a weighted index that takes into account the travel time factor and the working population within a corresponding district.

The travel time involved is compiled by using the Google map Distance Matrix API through the function "gmapsdistance" in R (i.e., an open-source programming language developed by GNU project [32]). Both the origin and the destination are the respective centroid of the Council Districts. If the centroid of a DC is located at sea, an approximated centroid within the land is selected. Using "Mass Transit" as the mode of transportation and setting the departure time as Monday, 8:00 a.m., a travel time matrix can be developed. For instance, the centroid of Wan Chai district is located near the Hong Kong Sanatorium \& Hospital; the "gmapdistance" in R will map out all travel times between this point and the remaining 17 DCs.

Travel time is not the only consideration in examining the accessibility of a district. The working population is also relevant in particular, when a spatial mismatch is a key concern. Therefore, the working population in each district at a particular year is used as a measure to weigh against the travel time aggregated. Based on the working population of each DC and travel times between districts, an accessibility index for 18 districts in Hong Kong is constructed.

\section{References}

1. Glaeser, E.L.; Luttmer, E.F.P. The Misallocation of Housing Under Rent Control. Am. Econ. Rev. 2003, 93, 1027-1046. [CrossRef]

2. Gyourko, J.; Linneman, P. Equity and efficiency aspects of rent control: An empirical study of New York City. J. Urban. Econ. 1989, 26, 54-74. [CrossRef]

3. Kain, J.F. Housing Segregation, Negro Employment, and Metropolitan Decentralization. Q. J. Econ. 1968, 82, 175. [CrossRef]

4. Temkin, K.M.; Theodos, B.; Price, D. Sharing Equity with Future Generations: An Evaluation of Long-Term Affordable Homeownership Programs in the USA. Hous. Stud. 2013, 28, 553-578. [CrossRef]

5. Bartel, A.P. The migration decision: What role does job mobility play? Am. Econ. Rev. 1979, 69, 775-786.

6. Goodman, A.C. A dynamic equilibrium model of housing demand and mobility with transac-tions costs. J. Hous. Econ. 1995, 4, 307-327. [CrossRef]

7. Rohe, W.M.; Stewart, L.S. Homeownership and neighborhood stability. Hous. Policy Debate 1996, 7, 37-81. [CrossRef]

8. Haurin, D.; Hendershott, P.; Wachter, S. Borrowing Constraints and the Tenure Choice of Young Households. J. Hous. Res. 1997, $8,137-154$.

9. Dietz, R.D.; Haurin, D.R. The social and private micro-level consequences of homeownership. J. Urban. Econ. 2003, 54, 401-450. [CrossRef]

10. Kluger, B.D.; Miller, N.G. Measuring Residential Real Estate Liquidity. Real Estate Econ. 1990, 18, 145-159. [CrossRef]

11. Krainer, J. A Theory of Liquidity in Residential Real Estate Markets. J. Urban. Econ. 2001, 49, 32-53. [CrossRef]

12. Genesove, D.; Han, L. Search and matching in the housing market. J. Urban. Econ. 2012, 72, 31-45. [CrossRef]

13. Sánchez, A.C.; Andrews, D. Residential Mobility and Public Policy in OECD Countries. OECD J. Econ. Stud. 2011, 2011, 1-22. [CrossRef] 
14. Gobillon, L.; Selod, H.; Zenou, Y. The Mechanisms of Spatial Mismatch. Urban. Stud. 2007, 44, 2401-2427. [CrossRef]

15. Alonso, W. Location and Land Use. Toward a General Theory of Land Rent; Harvard University Press: Cambridge, MA, USA, 1964.

16. Muth, R.F. Cities and Housing, The Spatial Pattern of Urban Residential Land Use; The University of Chicago Press: Chicago, IL, USA, 1969.

17. Tse, C.Y.; Chan, A.W. Estimating the commuting cost and commuting time property price gradients. Reg. Sci. Urban. Econ. 2003, 33, 745-767. [CrossRef]

18. Coulson, N.; Engle, R.F. Transportation costs and the rent gradient. J. Urban. Econ. 1987, 21, 287-297. [CrossRef]

19. Chica-Olmo, J.; Cano-Guervos, R.; Tamaris-Turizo, I. Determination of buffer zone for negative externalities: Effect on housing prices. Geogr. J. 2019, 185, 222-236. [CrossRef]

20. Leung, C.K.-Y.; Feng, D. What Drives the Property Price-Trading Volume Correlation? Evidence from a Commercial Real Estate Market. J. Real Estate Financ. Econ. 2005, 31, 241-255. [CrossRef]

21. Wong, S.K.; Yiu, C.Y.; Chau, K.W. Liquidity and information asymmetry in the real estate market. J. Real Estate Financ. Econ. 2012, 45, 49-62. [CrossRef]

22. Wong, Y.-C.; Liu, P.-W. The distribution of benefits among public housing tenants in Hong Kong and related policy issues. J. Urban. Econ. 1988, 23, 1-20. [CrossRef]

23. Lui, H.-K. The Redistributive Effect of Public Housing in Hong Kong. Urban. Stud. 2007, 44, 1937-1952. [CrossRef]

24. Lui, H.-K.; Suen, W. The effects of public housing on internal mobility in Hong Kong. J. Hous. Econ. 2011, 20, 15-29. [CrossRef]

25. Angrist, J.D.; Pischke, J.S. Mostly Harmless Econometrics: An Empiricist's Companion; Princeton University Press: Princeton, NJ, USA, 2008.

26. Wong, Y.C. Hong Kong Land for Hong Kong People: Fixing the Failure of Our Housing Policy; Hong Kong University Press: Hong Kong, China, 2015.

27. Chau, K.W.; Wong, S.K.; Yiu, C.Y. New Homeownership Scheme with a Time Limit (in Chinese). Hong Kong Economic Times. 15 May 2012. Available online: https:/ / paper.hket.com/article/787623/\%E5\%85\%A8\%E6\%96\%B0\%E5\%B1\%85\%E8\%80\%85\%E3\%80\% 8C\%E6\%9C\%89\%E6\%9C\%9F\%E3\%80\%8D\%E5\%B1\%8B\%20\%E5\%89\%B5\%E7\%A4\%BE\%E6\%9C\%83\%E4\%B8\%89\%E8\%B4\%8F (accessed on 7 February 2021).

28. Cheung, K.S. The Lock-in Effects of Subsidized Homeownership in Hong Kong. HKU Theses Online (HKUTO). 2017. Available online: http:/ / hub.hku.hk/handle/10722/257606 (accessed on 7 February 2021).

29. Wong, S.K. An immediate solution to supplying more subsidized homes (in Chinese). Headline Daily. 19 July 2011. Available online: http:/ / news.hkheadline.com/dailynews /headline_news_detail_columnist.asp?id=155189\&section_name=wtt\&kw=232 (accessed on 15 May 2012).

30. Eriksen, M.D.; Ross, A. Housing vouchers and the price of rental housing. Am. Econ. J. Econ. Policy 2015, 7, 154-176. [CrossRef]

31. Guarini, M.R.; Battisti, F. A Model to Assess the Feasibility of Public-Private Partnership for Social Housing. Buildings 2017, 7, 44. [CrossRef]

32. Gmapsdistance. Available online: https://cran.r-project.org/web/packages/gmapsdistance/readme/README.html (accessed on 7 February 2021). 